\title{
Configurações
}

Revista de sociologia

\section{Acidentes de trabalho: uma abordagem sociológica}

Occupational accidents: a sociological explanation

Accidents du travail : une explication sociologique

João Areosa e Tom Dwyer

\section{(2) OpenEdition}

\section{Journals}

Edição electrónica

URL: http://journals.openedition.org/configuracoes/213

DOI: $10.4000 /$ configuracoes.213

ISSN: 2182-7419

\section{Editora}

Centro de Investigação em Ciências Sociais

\section{Edição impressa}

Data de publição: 30 Junho 2010

Paginação: 107-128

ISSN: 1646-5075

\section{Refêrencia eletrónica}

João Areosa e Tom Dwyer, "Acidentes de trabalho: uma abordagem sociológica », Configurações [Online], 7 | 2010, posto online no dia 18 fevereiro 2012, consultado o 19 abril 2019. URL : http:// journals.openedition.org/configuracoes/213; DOI : 10.4000/configuracoes.213

Este documento foi criado de forma automática no dia 19 Abril 2019.

(c) CICS 


\section{Acidentes de trabalho: uma abordagem sociológica}

Occupational accidents: a sociological explanation

Accidents du travail : une explication sociologique

João Areosa and Tom Dwyer

\section{Introdução à noção de acidente}

1 Os acidentes sempre fizeram e sempre farão parte dos eventos ocorridos em sociedade, $\mathrm{e}$ isto pode explicar, em parte, o porquê de eles poderem ser considerados como um problema social. É verdade que os acidentes podem ocorrer em todos os lugares (escolas, casa, locais de trabalho, estradas, etc.), em diversas circunstâncias, e derivar de múltiplas causas. Esta fatalidade social à qual todos nós estamos sujeitos depende dos riscos e dos perigos que corremos ao longo das nossas vidas. Apesar de alguns acidentes serem dramáticos nas consequências que produzem, eles são por definição eventos relativamente raros, visto que representam desvios à normalidade. Em traços gerais, julgamos que não é possível prevenir e evitar todos os acidentes, mas estamos convictos de que as investigações sobre acidentes podem ajudar a prevenir alguns (Areosa, 2009a).

2 Os acidentes são eventos que ocorrem de forma repentina, mas às suas causas podem estar associados, simultaneamente, factores sincrónicos e diacrónicos. Em sentido etimológico, o termo "acidente" significa um qualquer evento não planeado, fortuito, imprevisto e fruto do acaso. Na linguagem do senso comum um acidente é entendido como algo nefasto, maléfico e aleatório que provoca danos ou prejuízos. Desta definição preliminar podemos diagnosticar a existência de uma impossibilidade empírica para controlar e antever todas as situações passíveis de causar acidentes. Até meados do século XVIII a noção ocidental de acidente (tal como a noção de risco) esteve associada a manifestações divinas; até este período as grandes catástrofes eram vistas como fruto da vontade dos Deuses. A laicização da catástrofe (Theys, 1987) começa a emergir após o 
terramoto de Lisboa de 1755 (Areosa, 2008) e surge como um pensamento fracturante dentro da visão social dominante acerca dos acidentes. A partir deste período os acidentes começam também a ser entendidos como resultado de condições naturais.

3 Ainda numa perspectiva histórica, facilmente se podem verifi car os inegáveis benefícios que a Revolução Industrial veio trazer para as sociedades modernas. Contudo, este "novo" período acarretou também alguns efeitos sociais adversos, nomeadamente ao nível da "produção" de acidentes. As novas formas de organização do trabalho, fruto da Revolução Industrial, são, em grande medida, responsáveis pela sinistralidade laboral massiva e sistemática que caracterizou

4 o mundo do trabalho nos últimos dois séculos (Pinto, 1996). É verdade que aos empregadores (em parte produtores dos discursos dominantes) interessa refutar qualquer responsabilidade sobre os acidentes de trabalho. Por isso, a sua visão quase sempre assentou no pressuposto da inevitabilidade dos acidentes (o designado preço a pagar pelo desenvolvimento industrial) ou a imprudência e respectiva culpabilização dos próprios trabalhadores (Español, 2001).

5 A partir da Revolução Industrial os acidentes passaram a incorporar uma nova dimensão de peso: a tecnologia. A interacção do homem com a tecnologia possibilitou a emergência de novas formas de acidentes. Podemos afi rmar que neste período houve uma transformação histórica na tipologia dos acidentes. Outra transformação importante nesta tipologia ocorreu a partir da segunda metade do século XX, através da emergência dos acidentes maiores (Turner, 1978; LaPorte e Consolini, 1991; Perrow, 1999; Reason, 2008; Burns e Machado, 2009). A título de exemplo, Marx e Engels foram dos primeiros autores a debater as condições adversas para a saúde e segurança dos trabalhadores durante a sua época. A reflexão de Marx (1966) incidiu sobre a questão da tecnologia devido a esta poder gerar a diminuição da necessidade de mão--de-obra. Após a emergência do taylorismo e da organização científica do trabalho os operários não perderam apenas a sua profissão, enquanto arte ou ofício (no sentido artesanal do termo), perderam também o seu próprio estilo e ritmo de trabalho, bem como o controlo sobre os seus movimentos. De certo modo, foram transformados em autómatos direccionados quase exclusivamente para maximizar a produção.

6 Desde o dealbar da Revolução Industrial até aos dias de hoje verifi caram-se profundas alterações na incidência dos acidentes, devido a múltiplos factores. Enquanto no início da Revolução Industrial os acidentes de trabalho com mineiros eram muito frequentes, actualmente encontramos esta característica nos operários da construção civil. Assim, as transformações no mundo do trabalho deram também origem à transformação na tipologia dos acidentes em contexto laboral.

7 Os discursos leigos sobre os acidentes foram sendo reajustados ao longo das últimas décadas (independentemente de serem produzidos pelos próprios protagonistas ou por simples observadores), mas continuam fortemente dominados pela ideia de que os acidentes são fenómenos isolados, descontínuos, que surgem de forma imprevisível e, por isso mesmo, são insusceptíveis de apreensão racional que vá muito para além de uma análise casuística. Pinto (1996) sustenta que esta visão sobre a sinistralidade laboral é bastante redutora, visto que no seu estudo sobre os acidentes de trabalho na construção civil pôde encontrar determinadas regularidades e permanências que contrariam estes pressupostos. Os acidentes de trabalho não são acontecimentos passíveis de ocorrer numa espécie de "vácuo social"; pelo contrário, eles percorrem globalmente o mundo do trabalho, o seu espaço de produção e de existência social, embora de forma não 
homogénea. Parece-nos indiscutível que os acidentes de trabalho podem ser influenciados por factores socioculturais. Para além disso, as percepções dos trabalhadores sobre os acidentes de trabalho, mesmo que, por vezes, algo distorcidas em termos de rigor e objectividade, não deixam de ser uma dimensão essencial para a compreensão e entendimento deste problema.

Por outras palavras: as evidências e visões sobre os acidentes de trabalho partilhadas pelos actores sociais são sempre, independentemente dos equívocos lógico-intelectuais em que assentam, uma componente essencial do sistema de determinações da sinistralidade concreta (e de resto, também, um dos elos mais resistentes a intervenções de natureza preventiva neste domínio). Nem de outra forma se encontraria justificação para invocar a "dimensão cultural" dos acidentes de trabalho. (Pinto, 1996: 95)

O problema dos acidentes de trabalho pode ser visto a partir de duas lógicas distintas: a lógica preventiva e a da reparação. À refutação, por parte de alguns sistemas jurídicos oficiais, da concepção dos acidentes enquanto eventos exclusivamente imprevisíveis ou fruto da imprudência dos trabalhadores, fi cou subjacente a ideia da responsabilidade pelo risco gerado nos locais de trabalho (o que veio abrir espaço para outros actores responsáveis pelos sinistros); este foi um marco histórico para os movimentos sociais do século XIX que lutavam por melhores condições de trabalho e maior justiça social no âmbito laboral. Estes movimentos ocorreram essencialmente em França, Inglaterra e Estados Unidos. A criação de seguros obrigatórios para os acidentes de trabalho foi, talvez, a última grande conquista para uma maior equidade social em relação aos acidentes de trabalho. Como afi rma Pinto:

O caso francês pode aliás afirmar-se que, já a partir de 1841, com a infl exão da jurisprudência no sentido de, salvo prova em contrário, se imputar à entidade patronal responsabilidades pela indemnização dos acidentados, foram concedidos aos assalariados alguns instrumentos básicos de defesa nesta matéria. Mesmo assim, e como nota Remi Lenoir, "para além das dificuldades que o assalariado encontrava para aduzir a prova da culpabilidade do empregador, por força do desaparecimento dos indícios e do silêncio das testemunhas, sobrevinham inúmeros acidentes sem que se tornasse possível imputar uma 'falta' a quem quer que fosse, de modo que a maior parte das vítimas eram privadas de qualquer espécie de reparação". (Pinto, 1996: 104)

9 Segundo Ewald (in Pinto, 1996: 105), se considerarmos que os acidentes de trabalho resultam do desenvolvimento tecnológico e dos processos de industrialização, então, não devem ser os empregadores os principais responsáveis pelos acidentes, mas antes, a ciência, a técnica e o progresso. Naturalmente que esta afirmação não está isenta de controvérsia, mas até podemos considerar que esta perspectiva traduz alguma veracidade. Na mesma linha de pensamento, Ulrich Beck (1992) e Charles Perrow (1999) corroboram a ideia de que a ciência e a tecnologia acarretam novas formas de risco para a modernidade, passíveis de originar acidentes ou efeitos devastadores.

10 Os acidentes tendem a ser eventos localizados no tempo e no espaço e emergem a partir de um contexto "histórico" específico. Segundo Pinto (1996), é difícil recusar a ideia de que os acidentes de trabalho se encontram profundamente interligados com as características dos processos de trabalho. Assim, os acidentes podem ser vistos como uma variação das situações normais de trabalho. Na perspectiva de Furnham (1992: 258) os acidentes, por vezes, são definidos através das suas consequências, em vez de serem procurados os seus antecedentes. Todavia, tentar encontrar as causas dos acidentes é um aspecto fundamental, sabendo que estes podem ter origens muito distintas. Furnham afi 
rma que a compreensão dos acidentes deve estar centrada também em certos detalhes, nomeadamente, a descrição da situação, processos ou circunstâncias e aspectos pessoais das vítimas. Porém, é pertinente ter em linha de conta que quase todos os acidentes apresentam algumas "zonas sombrias" de difícil compreensão, o que dificulta a sua análise e prevenção. Aliás, Hollnagel (2004) preconiza que nunca se consegue descobrir completamente todos os factores subjacentes aos acidentes.

11 As ciências sociais vieram, de algum modo, tentar desmistificar a essência da etimologia do acidente, à qual estava subjacente a ideia quase exclusiva de eventos aleatórios ou fortuitos. Embora estas componentes possam contribuir parcialmente para a explicação dos sinistros, existem outras dimensões que não podem ser esquecidas. É por este motivo que Dwyer e Elgstrand (2009) defendem que é necessário um novo paradigma para a segurança no trabalho, onde sejam incluídos aspectos de natureza social. Para além disso, ainda subsistem, actualmente, alguns enviesamentos (por defeito) na contabilização do número de acidentes de trabalho. Esta situação leva Pinto (1996: 95) a interrogar-se se esta questão é um problema metodológico ou político.

\section{Revisitando a teoria sociológica de Dwyer para os acidentes de trabalho}

12 O entendimento sobre os múltiplos factores que podem contribuir para os acidentes tem sofrido significativas alterações nas últimas duas ou três décadas. Os acidentes deixaram de ser concebidos apenas como fenómenos fortuitos e individuais, passando também a ser integrados na sua análise factores sociais e organizacionais (Hovden, Albrechtsen e Herrera, 2010). É verdade que os acidentes são eventos expectáveis no mundo do trabalho, tendo em conta a extraordinária diversidade de riscos que os diferentes tipos de trabalho podem incorporar. A história dos acidentes de trabalho tem demonstrado que, à medida que se vão reduzindo certos tipos de acidentes, também vão emergindo novos tipos de sinistralidade (Dwyer, 2000a). Qualquer local de trabalho implica a presença de determinados perigos, variáveis de organização para organização. Deste modo, os acidentes de trabalho decorrem da presença de perigos e da exposição dos trabalhadores aos riscos laborais (Areosa, 2003, 2005). Para além disso, alguns riscos "insuspeitos" nos locais de trabalho são susceptíveis de poder causar graves acidentes (Granjo, 2004). É pertinente lembrar que os acidentes podem acarretar problemas graves para os trabalhadores (lesões permanentes ou a própria morte), mas as consequências destes eventos vão muito para além do drama inerente ao próprio trabalhador sinistrado, pois podem também afectar, ainda que indirectamente, as suas famílias, os seus colegas de trabalho, os seus empregadores e a sociedade em geral.

No início da década de setenta, Hale e Hale (1972) apelavam à urgente necessidade de criar novas teorias e novos métodos para compreender o fenómeno dos acidentes. Dentro da teoria social existem alguns modelos de elevada relevância para a compreensão dos acidentes, particularmente o paradigma sociotécnico dos desastres de origem humana, elaborado por Turner (1978); a abordagem sistémica dos acidentes, onde destacamos a perspectiva dos "aci-dentes normais" preconizada por Perrow (1999); o modelo das High Reliability Organizations protagonizado, entre outros, por Weick (1987), Roberts (1990) e Weick e Stucliffe (2007); e, finalmente, o modelo do erro humano e dos acidentes organizacionais, apresentado por Reason $(1990,1997,2008)$. Porém, o referido apelo 
efectuado por Hale e Hale (1972) motivou, em parte, a elaboração de uma teoria sociológica para compreender os acidentes de trabalho (Dwyer, 1989, 1991, 2000b, 2006). ${ }^{1}$ Para dar sequência a esta demanda, foram observadas diversas relações sociais nos locais de trabalho, por vezes, separadas analiticamente enquanto objecto de estudo, mas profundamente interligadas ao nível empírico. A tese central da teoria sociológica de Dwyer preconiza que os acidentes de trabalho são, em grande medida, o resultado de relações sociais. De certo modo, podemos afirmar que este modelo (concebido essencialmente como fruto de relações sociais) está ancorado quer na perspectiva de Durkheim, na qual se defende que o social deve ser explicado pelo social, quer na perspec tiva fenomenológica de Schutz, derivada da sociologia Weberiana (cf. Dwyer, 2006).

No âmago da teoria sociológica de Dwyer existem, essencialmente, três níveis sociais com capacidade para explicar o desenvolvimento das relações entre empregadores e trabalhadores - a recompensa, o comando e o organizacional - e, por arrastamento, do próprio fenómeno dos acidentes de trabalho; a estes três níveis Dwyer acrescenta um quarto, de carácter não-social, designado como indivíduo-membro. A importância de cada um destes níveis é construída nos próprios locais de trabalho, não é dada antecipadamente; logo, a importância de um nível num determinado contexto não significa que ele tenha o mesmo "peso" noutra realidade sociolaboral distinta. Em termos metodológicos, são testadas quatro hipóteses de análise ${ }^{2}$ a partir de uma observação directa e participante, onde é privilegiada uma certa dialéctica "negocial" entre o conheci mento do especialista (investigador) e o saber prático dos sujeitos observados (objecto de estudo). Esta situação caracteriza, em parte, a originalidade e pertinência da pesquisa sociológica protagonizada por Dwyer $(1991,2006)$.

Nesta perspectiva, os acidentes de trabalho dependem da relação directa ou indirecta dos trabalhadores com os riscos. Os acidentes são também vistos como uma situação de erro específico, produzido organizacionalmente, fruto do funcionamento e interacção das quatro dimensões referidas na figura 1. Nesta fi gura foi representado o modelo que concebe como as relações sociais de trabalho e o nível indivíduo-membro podem interagir de modo a produzir acidentes. 


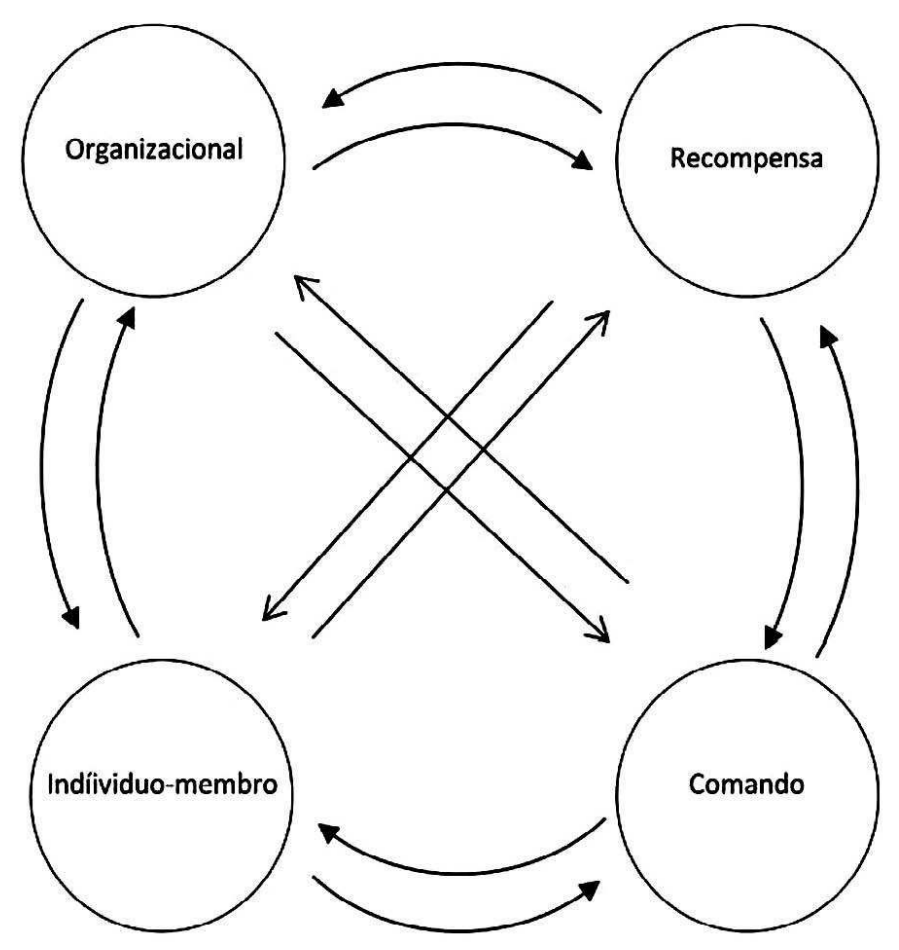

FONTE: ADAPTADO DE DWYER (2006: 142).

Vejamos agora com maior detalhe cada um dos quatro níveis concebidos por Dwyer na sua teoria sociológica dos acidentes de trabalho. 0 primeiro nível

- a recompensa - está relacionado com a utilização de incentivos para gerir a relação das pessoas com o seu trabalho. Estes incentivos podem ser subdivididos em três factores distintos: 1) materiais ou financeiros relacionados com a intensificação do trabalho; 2) ampliação (prolongamento) do trabalho, por exemplo, através do recurso a horas extraordinárias; 3) recompensas simbólicas.

Os incentivos financeiros que visam o aumento da produtividade dão normalmente origem à execução de tarefas de forma mais rápida (aumentando simultaneamente o cansaço dos trabalhadores e o número de erros ou falhas) em detrimento, por exemplo, do cumprimento das normas e regras de segurança estabelecidas para aquela tarefa. As recompensas materiais podem também influenciar a aceitação da execução de tarefas de maior risco, a troco de dinheiro, pelos trabalhadores. Existe uma certa tendência para os problemas resultantes dos incentivos serem escamoteados, devido à aparente relação mutualista que parece resultar para empregadores e trabalhadores; ou seja, os primeiros vêem a sua produção aumentada, enquanto os segundos vêem os seus salários alargados. Todavia, os custos subjacentes a esta prática estão situados, por exemplo, no aumento do número de acidentes (McKelvey et al., 1973 in Dwyer, 2006: 153) e em todas as consequências que daí advêm. Posteriormente, observou-se que esta prática acarretava ainda outros problemas. Uma das desvantagens para os empregadores que recorriam à utilização de incentivos económicos para o aumento da produção era que este factor acabava por conduzir a uma certa rejeição pelos trabalhadores das tarefas que não seriam alvo de incentivos. Este modelo de gestão provocava também o "corte" de algumas etapas 
supostamente consideradas dispensáveis, ou a diminuição da produtividade, quando as metas para obter os incentivos económicos eram demasiado exigentes. Para ilustrar esta situação, verifica-se, por exemplo, que "andaimes são erguidos e não adequadamente fixados; máquinas que requerem manutenção são colocadas em funcionamento sempre que reparos preventivos implicam interrupção do trabalho que leve a reduções no pagamento; restos são deixados para outros limparem; o carvão subterrâneo é extraído à custa de escorar o teto; cálculos da produção fraudados" (Dwyer, 2006: 147).

19 A ampliação do trabalho é uma relação social diferente da anterior, dado que não está assente na intensificação do esforço, mas sim no prolongamento do tempo de trabalho. Isto significa que os trabalhadores podem obter melhores salários através do aumento da sua carga horária (quanto maior for o número de horas extraordinárias trabalhadas, maior será o salário obtido). Por parte dos empregadores o recurso à ampliação do trabalho pode dever-se à escassez de trabalhadores, a prazos apertados para a entrega da sua produção ou a elevados custos na contratação de outros trabalhadores. Porém, o prolongamento do horário de trabalho torna os trabalhadores mais vulneráveis a sofrerem acidentes de trabalho, devido ao cansaço acumulado na jornada de trabalho (Areosa, 2010).

20 As recompensas simbólicas estão articuladas com dimensões culturais dos próprios trabalhadores, tais como o prestígio, o estatuto social, a estima ou o cumprimento de "rituais" de integração no grupo ao qual se quer pertencer. Alguns antropólogos estudaram a questão das recompensas simbólicas no trabalho e verificaram, por exemplo, que os índios norte-americanos que trabalharam na construção de arranha-céus executavam o seu trabalho sem a menor segurança laboral. Esta situação devia-se à aceitação dos perigos por parte destes actores sociais, visto que a deliberada exposição ao risco era entendida como um acto heróico e, simultaneamente, como um mecanismo de reforço dos seus valores culturais tradicionais de guerreiros (bravura, audácia, coragem, etc.), por contraposição aos valores tendencialmente preventivos das sociedades modernas.

21 Todas as situações descritas anteriormente podem resultar num aumento do número de acidentes de trabalho, considerando a aceitação de riscos mais elevados fomentada pelos três tipos de relações sociais no nível de recompensa (material, ampliação do trabalho e recompensa simbólica). Aliás, Dwyer (2006) cita também outros estudos onde se verifica que existe uma relação directa entre o aumento de horas trabalhadas e o aumento do número de acidentes de trabalho.

O segundo nível da teoria sociológica dos acidentes de trabalho, designado por comando, está relacionado com a forma como os empregadores tentam gerir as relações dos trabalhadores com o seu trabalho, através de um controlo directo ou indirecto sobre as suas acções. Regra geral, os trabalhadores tentam resistir a formas de controlo mais "apertadas" (que tendem a inibir a sua autonomia). 0 conflito latente entre empregadores e trabalhadores pode ser explicado, em parte, através do exercício desta forma de poder e de dominação. De certo modo, podemos afirmar que para contrabalançar um poder dominante do empregador existe um contrapoder dominado dos trabalhadores e este último pode assumir formas e estratégias muito diversifi cadas.

23 A dinâmica do nível comando é também ela produzida através de três tipos de relações sociais distintas: 1) o autoritarismo, 2) a desintegração do grupo de trabalho e 3) a servidão voluntária. As estratégias de autoritarismo utilizadas por alguns empregadores são concebidas não tanto como um mecanismo de defesa da segurança dos trabalhadores, 
mas antes como uma tentativa deliberada para garantir que o trabalho seja executado de forma célere. Em diversas pesquisas de campo, na área da construção civil francesa, verificou-se a existência de um número significativo de trabalhadores "insatisfeitos", devido ao seu trabalho ser gerido pelo autoritarismo. Estes trabalhadores compreendiam que este factor era responsável por uma parte dos acidentes ocorridos no seu local de trabalho (Dwyer, 1989: 29). Todavia, se um trabalhador reclamar das más condições de trabalho às quais está sujeito, o seu empregador pode encontrar determinados enredos para terminar esta relação contratual (despedimento). Porém, se as condições de trabalho são más e não forem corrigidas, provavelmente irá haver mais acidentes; este é um dos aspectos em que se torna visível a estreita relação entre autoritarismo e acidentes de trabalho, ou seja, o autoritarismo pode produzir acidentes (Dwyer, 2006: 174).

A desintegração do grupo de trabalho pode ser efectuada, por exemplo, através de uma elevada rotatividade dos trabalhadores na empresa. Os empregadores procuram eliminar as ameaças que os grupos de trabalho coesos ou integrados podem acarretar para si, no entanto, utilizam a desintegração sem que isso impeça o desenvolvimento das tarefas laborais. A desintegração do grupo de trabalho pode resultar em acidentes quando as pessoas que trabalham em tarefas que requerem um trabalho interdependente não se compreendem. A alta rotatividade de trabalhadores e os grupos onde as pessoas não falam a mesma língua são alguns factores que produzem esta relação social. É pertinente lembrar que um grupo de trabalho integrado pode constituir a base de resistência dos trabalhadores à imposição de trabalhos perigosos.

A servidão voluntária é a relação social que está relacionada com a execução de trabalhos difíceis ou perigosos, sem que haja qualquer oposição por parte dos trabalhadores que não recebem recompensas extraordinárias por esse tipo de trabalhos. De certo modo, é uma aceitação quase fatalista das difi culdades do trabalho e dos riscos laborais mais elevados, na medida em que os trabalhadores têm plena consciência dessas dificuldades ou riscos. Ambientes de trabalho insalubres podem ser dominados por esta relação. Para facilitar a subserviência, os empregadores podem recorrer a trabalhadores que eles julgam mais propensos à servilidade, particularmente, mulheres, deficientes ou imigran tes ilegais. Em resumo, verifica-se que, nesta relação social, as acções dos trabalhadores estão em harmonia com os objectivos do empregador (Dwyer, 2006: 167); mas, apesar de este tipo de trabalhadores ser facilmente manipulável, esta política não está isenta de desvantagens para o empregador, pois promove a excessiva passividade na execução do trabalho.

Nesta teoria sociológica destaca-se ainda o papel positivo para a prevenção de acidentes que alguns sindicatos podem desempenhar, ao combaterem dentro das empresas estes três tipos de relações sociais (autoritarismo, desintegração do grupo de trabalho e servidão voluntária). As relações que se estabelecem entre trabalhadores e hierarquias são um aspecto decisivo nas relações sociais de trabalho, particularmente na forma de dirigir a execução do trabalho. Segundo Freire (1991), os encarregados e capatazes da construção civil, enquanto agentes de comando de "primeira linha" (hierarquia directa), podem ter um papel importante no aumento ou diminuição do número de acidentes de trabalho, devido ao papel específico que desempenham dentro das organizações. Se a sua sensibilidade para os temas da segurança no trabalho for signifi cativa, o poder e a autoridade inerentes ao seu cargo podem constituir-se como factores inibidores para os acidentes. Aliás, esta perspectiva vai ao encontro de um dos dez axiomas da segurança 
industrial, apresentados por Heinrich (1931), que defende que os supervisores e capatazes são agentes-chave para a prevenção de acidentes.

Dwyer define o nível comando, em grande medida, por relações de poder. Segundo esta perspectiva, a utilização do poder serve para combater os comportamentos considerados indesejados e tanto pode ser usado pelo empregador (e respectiva cadeia hierárquica), como pelos próprios trabalhadores (entre pares). 0 poder dentro das relações sociais pode ser utilizado na prevenção de acidentes, por exemplo, através da punição de práticas e comportamentos defi nidos como inseguros. No entanto, algumas pesquisas indicam que as medidas dis-ciplinares são capazes de reduzir mais o registo formal de acidentes do que os próprios acidentes (Dwyer, 2006: 185). Este último aspecto é importante, visto que tem subjacente o medo que os trabalhadores têm de serem punidos disciplinarmente por sofrerem acidentes. Este facto pode levá-los a não os declarar. Para evitar situações desta natureza algumas organizações preferem transferir a responsabilidade da vigilância para os próprios trabalhadores. Esta estratégia é designada como autocomando, ou seja, são os próprios pares que impõem sanções àqueles que agem de forma perigosa. Alguns estudos (cf. Dwyer, 2006) sugerem que a maioria dos trabalhadores tem preferência pelo modelo de autocomando, em detrimento de programas de segurança organizados pela empresa. Todavia, ainda não existem estudos suficientes para demonstrar que o modelo de autocomando seja, no geral, mais efi caz na prevenção de acidentes.

O terceiro nível apresentado na teoria sociológica de Dwyer (2006) é designado por organizacional. Neste nível é possível identificar três tipos distintos de relações sociais: 1) a subqualificação; 2) a rotina; e 3) a desorganização. Na subqualificação pretende-se observar se o tipo de conhecimento dos trabalhadores sobre as suas tarefas é insuficiente, visto que a falta de conhecimento pode dar origem a uma incapacidade para executar as tarefas laborais em segurança. Por sua vez, esta incapacidade pode depender da falta de formação específi ca ou de um enviesamento na capacidade de tradução do conhecimento formal em conhecimento prático.

29 A introdução de novas técnicas e/ou tecnologias nos locais de trabalho gera, potencialmente, um novo factor de risco (Areosa, 2009b), que se pode traduzir num aumento da ocorrência de acidentes. A génese destes acidentes pode ser encontrada numa ruptura entre a experiência e as qualificações de trabalho, desenvolvida nas funções ou tarefas anteriores, e na inexperiência e falta de qualificações perante a nova situação de trabalho. Nestes casos os trabalhadores ainda não desenvolveram os mecanismos necessários para "dominar" os novos riscos, ou seja, ainda não habituaram o seu corpo ou os seus conhecimentos às novas situações de riscos, resultantes das alterações dos seus locais de trabalho (Pinto, 1996).

Uma parte significativa da rotinização do trabalho está associada à organização científica do trabalho, isto é, devido ao avanço dos princípios de gestão tayloristas e fordistas. Isto resultou de uma semi-automatização e simplifi cação do trabalho, que acarretou diversas consequências, particularmente a rotinização das tarefas para os trabalhadores menos qualificados. A literatura sobre as percepções de riscos (cf. Areosa, 2007, 2009c) refere que as tarefas executadas com pouca frequência são mais susceptíveis de originar acidentes ${ }^{3}$; isto pode estar relacionado com a falta de determinados hábitos, com a ausência de adap tação perante determinados riscos ou ainda com a falta de qualifi cações. Para compreender alguns tipos de acidentes é ainda importante considerar as estratégias de gestão cognitiva dos trabalhadores (Amalberti, 1996) ou a questão dos gestos voluntários e involuntários, particularmente em trabalhos monótonos e cadenciados. Se um 
trabalhador de uma linha de montagem é excepcionalmente confrontado com uma nova situação de trabalho, ele até pode compreendê-la, mas o designado refl exo condicionado anterior continua e isso pode explicar alguns tipos de acidentes. Dwyer (2006) define este tipo de acidentes como resultado de uma relação social do trabalho de rotina.

31 A literatura sobre acidentes tem vindo a demonstrar que a execução de tarefas designadas de rotina é passível de gerar algumas "armadilhas cognitivas" aos trabalhadores que operam nos sistemas. Estas armadilhas podem acontecer em qualquer tipo de trabalho (quer em situações relativamente simples, quer em situações complexas). Reason e Hobbs (2003) afirmam que a familiaridade com determinadas situações pode conduzir o nosso comportamento através de certos automatismos de rotina. A experiência em executar determinadas tarefas pode dar origem a que os trabalhadores tendam a reduzir o seu esforço mental, actuando como se tivessem accionado uma espécie de piloto automático. Assim, os seus saberes de rotina podem, por vezes, conduzir as suas acções e isto é susceptível de se tornar perigoso, pois os trabalhadores podem actuar de forma contrária à que pretendiam.

32 A terceira relação apontada neste nível é a desorganização, que pode manifestar-se de diversas formas. Regra geral, quando o conhecimento inerente a uma determinada tarefa não é transmitido de forma adequada à pessoa que entra em contacto com essa mesma tarefa, podemos afirmar que esse trabalho é administrado por meio de uma relação social de desorganização. Outro exemplo desta relação pode ser identificado quando o próprio empregador efectua uma concepção "defeituosa" ou inadequada da tarefa que irá ser executada pelo trabalhador. A falta de manutenção de máquinas, equipamentos ou infraestruturas, a falta de limpeza e a desarrumação dos locais de trabalho são também factores que geram desorganização. Um controlo desadequado sobre o efectivo cumprimento das regras, normas e procedimentos de trabalho (falta de comando) contribui para produzir a desorganização. Tal como afi rma Dwyer:

Frequentemente a desorganização introduz novos problemas no processo produtivo. No caso de quebra de equipamentos e em situações semelhantes, observa-se que, muitas vezes, os trabalhadores atuam fora de suas áreas especia lizadas para garantir a produção. Modificam as suas tarefas para fazer isso e, a partir de então, seu trabalho pode passar a ser gerenciado por uma subqualifi cação. Nas minas de ferro francesas, Defoin encontrou índices de acidentes, nas tarefas de manutenção, quatro vezes maiores do que no trabalho normal. Essa estatística provavelmente mistura desorganização e subqualifi cação. (Dwyer, 2006: 203)

O quarto e último nível apresentado nesta teoria sociológica dos acidentes é o único nível não-social e é designado por indivíduo-membro. 0 seu cariz está centrado numa "sociologia do sujeito", que defende que o indivíduo detém uma certa autonomia para agir, independentemente dos constrangimentos impostos pelas relações sociais e organizacionais. Metaforicamente, é a parte do trabalhador que se consegue "libertar" da influência dos três grandes níveis sociais descritos anteriormente. No fundo, será o reconhecimento por parte da teoria sociológica de Dwyer que existem factores não sociais susceptíveis de infl uenciar a ocorrência de acidentes de trabalho. Um dos aspectos importantes desta dimensão está relacionado com a tentativa de explicar a ocorrência de “acidentes" provocados por autolesão (actos intencionalmente fomentados pelo traba lhador) ou por outro tipo de acções de natureza individual. Recorrendo a alguns exemplos, Dwyer tenta explicar qual a importância do nível indivíduo-membro no seio das relações de trabalho, ao afirmar que: 
O trabalhador expressa-se de forma individual ao chegar ao local de trabalho contente, porque talvez tenha acabado de ganhar um filho ou por estar intoxicado. o trabalhador pode agir individualmente em um dos níveis sociais para reforçar o seu poder ou o do patrão nesse nível. o indivíduo que sabota a linha de montagem, o que organiza clandestinamente um sindicato ou o que viola as normas de produtividade coletivas numa fábrica que paga por produção, todos eles expressam dimensões diferentes desse nível de realidade. 0 sabotador recusa-se a aceitar o controle de seu ritmo de trabalho imposto pela linha de montagem. $O$ sindicalista busca contestar coletivamente o poder de controle de seus patrões. O violador das normas coletivas tenta aumentar seus ganhos aceitando as defi nições do patrão e rejeitando as de seus colegas. (Dwyer, 1989: 27)

$\mathrm{Na}$ teoria sociológica dos acidentes de trabalho proposta por Dwyer é apresentada uma abordagem para a explicação dos acidentes através da observação das relações sociais dentro das organizações. As relações sociais de trabalho são entendidas como a forma pela qual os próprios trabalhadores gerem o seu relacionamento com o trabalho. Esta perspectiva discute que os acidentes são essencialmente fruto das relações sociais de trabalho e, por isso, só podem ser prevenidos através de alterações em algumas destas relações. Assim, parece pertinente compreender quais são as relações sociais que produzem erros e, por consequência, acidentes. A capacidade de influência de cada um dos níveis referidos pode variar mediante cada contexto ou local de trabalho, dependendo das estratégias de empregadores e trabalhadores. A principal tese desta teoria preconiza que quanto maior for o peso de um nível nas relações sociais de trabalho em relação à gestão dos perigos, maior será a proporção de acidentes causados por esse mesmo nível.

Apesar de a teoria sociológica de Dwyer considerar os quatro níveis, referidos na figura 1 como os mais importantes para a compreensão e explicação da maioria dos acidentes de trabalho, ela não deixa de reconhecer a existência de outros aspectos interessantes para um melhor entendimento acerca da possível complexidade multicausal dos acidentes de trabalho, incorporando alguns resultados validados em outros estudos empíricos. É verdade que Dwyer trabalha com a ideia de monocausalidade dos acidentes (causa principal ou fundamental), devido a este aspecto facilitar a questão da responsabilização, ou seja, tenta evitar a diluição da responsabilidade provocada pelas teorias que se baseiam na multicausalidade. Autores como Reason (1990; 1997), Rasmussen (1997), Perrow (1999) e Hollnagel (2004) defendem que os acidentes podem resultar da articulação simultânea ou sequencial de vários factores ou causas. Isto significa que as causas podem estar, por exemplo, ligadas em rede e que só a sua articulação permite a efectiva ocorrência de determinado evento. Por outras palavras, a teoria de Dwyer (2006: 235-236) reconhece explicitamente a interligação entre os níveis da realidade social e diferentes relações sociais na produção do acidente, mas procura forçar os actores sociais a serem responsáveis pelas suas escolhas, de modo a que isto permita determinar "a causa" do acidente. Todavia, esta perspectiva acaba por, em certos casos, limitar a análise de outros factores, que podem igualmente contribuir para a ocorrência dos acidentes.

De seguida iremos apresentar alguns destes aspectos que acabam por se tornar relevantes para o esclarecimento dos acidentes de trabalho, enquanto fenómenos sociais complexos, bem como para ampliar as fronteiras da própria teoria sociológica dos acidentes. 


\section{Os acidentes e as teias das relações sociais no trabalho: a reinterpretação de alguns resultados de estudos empíricos}

Alguns estudos (cf. Dwyer, 2006) revelam que as queixas dos trabalhadores relativamente à má qualidade do sono (dormir pouco, insónias, etc.) parecem estar relacionadas quer com o aumento do número de acidentes, quer com a sua maior gravidade. Também a "variável" alimentação sugere a existência de algum impacto negativo nos trabalhadores, nomeadamente nos subnutridos. A relação entre a alimentação e os acidentes de trabalho foi pesquisada em alguns trabalhadores da construção civil franceses de origem muçulmana, tendo sido observado que, durante o Ramadão, estes trabalhadores estavam mais vulneráveis a sofrerem acidentes de trabalho.

Segundo Pinto (1996) a dimensão da empresa, em termos de número de trabalhadores, parece ser também um factor importante no estudo da sinistralidade laboral, visto que as empresas de maior dimensão tendem a ter, proporcionalmente, menos acidentes. Já Schwartz (1987 in Dwyer, 2006) tentou associar o acidente do Space Shuttle Challenger a algumas características narcísicas das hierarquias de topo da NASA que coordenavam esta missão.

As estratégias organizacionais para a redução de acidentes podem passar, entre muitas outras medidas, por atribuir incentivos aos trabalhadores não sinistrados. Esta posição por parte do empregador pode, em determinados casos, levar os trabalhadores a não declararem os acidentes sofridos, de modo a garantirem as recompensas estipuladas. As barreiras linguísticas e as consequentes dificuldades de comunicação que alguns trabalhadores estrangeiros têm de ultrapassar são também vistas como um factor que pode conduzir ao aumento dos acidentes de trabalho. A relação entre o ruído elevado em alguns locais de trabalho e a ocorrência de acidentes é um campo relativamente bem estudado, onde se conclui que o ruído tende a aumentar os acidentes (Arezes, 2002). Nestas situações a utilização de protectores auriculares é normalmente recomendada; porém, em determinados contextos verificou-se que a utilização de protectores auriculares em locais de trabalho ruidosos pode aumentar o número de acidentes, devido à inibição da comunicação e da percepção de outros riscos por parte dos trabalhadores, nomeadamente aqueles que podem ser percebidos através da audição (circulação de máquinas, sinais de alarme sonoros, etc.). Neste caso, se recorrêssemos à teoria de Dwyer (2006), estaríamos a falar da desintegração do grupo de trabalho.

40 Em determinados contextos específicos os factores culturais são também apresentados como responsáveis por elevadas taxas de sinistralidade laboral. Durante o período do apartheid, na África do Sul, o elevado número de acidentes de trabalho com mineiros negros foi reconhecido como uma incapacidade deste grupo de recusar a exposição aos riscos mais graves, imposto pelo "despotismo racial" ao qual estavam sujeitos (Leger, 1986).

41 Alguns estudos apontam para que a elevada coesão das equipas de trabalho possa constituir-se como um factor importante para a prevenção de acidentes de trabalho (Hunter, 2002). Observou-se esta situação em alguns casos onde os próprios trabalhadores podiam escolher os seus parceiros para trabalhar directamente consigo. A redução de 
acidentes parece derivar da coesão de grupo e do bom relacionamento entre pares; isto parece indicar que as equipas mais coesas tendem a autoproteger-se (Areosa, 2010).

Em contexto industrial, certos estudos revelam que alguns trabalhadores tentam evitar pensar em todos os riscos do seu trabalho, caso contrário, isto poderia acarretar alguns problemas psíquicos difíceis de ultrapassar. A psicopatologia do trabalho aborda normalmente este tema (Dejours, 1991). Esta questão é também transportada para a investigação sociológica (Dwyer, 2006), onde se questiona quais as relações sociais que podem contribuir para os trabalhadores aceitarem determinados riscos inerentes ao seu local de trabalho. Além das recompensas ou da servidão voluntária, outro aspecto que pode ser frisado é o facto de a segurança não ser normalmente um tema predominante na mente da maioria dos trabalhadores. Isto não significa que os trabalhadores ignorem propositadamente os aspectos da segurança, mas o desenvolvimento e a pressão do seu trabalho podem obrigá-los a adoptar outro tipo de prioridades.

Em determinadas circunstâncias alguns trabalhadores têm de enfrentar um forte dilema na execução de algumas tarefas mais perigosas, nas quais são identificadas condições de trabalho inseguras. Se, por um lado, pode haver por parte dos trabalhadores uma consciência fidedigna dos perigos e dos riscos que essas actividades envolvem; por outro lado, podem revelar medo ou receio em recusarem a execução deste tipo de trabalhos, devido às possíveis retaliações por parte das hierarquias organizacionais. Esta situação pode influenciar a ocorrência de acidentes de trabalho, caso os trabalhadores assumam uma postura de resignação perante as más condições de trabalho e não tentem pressionar os empregadores para as melhorarem. Esta perspectiva vai ao encontro de um dos pilares da teoria sociológica dos acidentes (Dwyer, 2006), que defende que os acidentes de trabalho são também fruto de relações sociais de poder.

Por vezes, existe uma visão descoincidente sobre os níveis de risco entre quem concebe e organiza o modelo de trabalho e os próprios trabalhadores que operam os sistemas. Tal pode ser considerado como um aspecto importante para a ocorrência de acidentes. Se a organização ou empresa estipula uma determinada tarefa como sendo segura, mas os trabalhadores (através do contacto empírico que têm com o trabalho) a consideram insegura, podemos entrar aqui na polémica discussão entre as perspectivas de riscos “objectivos" e riscos "subjectivos" (Sjoberg, 1999). É verdade que, na maioria das situações, os trabalhadores tendem a aceitar a visão dos empregadores, estando subjacente a ideia de que, se determinada situação não fosse segura, não seria permitida. Porém, algumas situações fogem a esta "regra", tal como demonstra o exemplo seguinte dado por Dwyer:

Um trabalhador francês da construção civil recusou-se a usar cinto de segurança fornecido para a sua tarefa. Ele disse que os procedimentos de enganchar e de desenganchar necessários para mudar sua posição eram muito mais perigosos do que simplesmente não usar o cinto. (Sua rejeição foi formulada sem que ele tivesse o menor conhecimento de um estudo francês que demonstrou que a maioria dos acidentes acontecia a alguns usuários desse tipo de cinto durante esses procedimentos). (Dwyer, 2006: 183)

O exemplo anterior demonstra que a segurança no trabalho enfrenta vários problemas de difícil resolução. Para além disso, pode acarretar fortes dilemas para os especialistas em segurança, isto é, a tentativa de minimizar um risco (por exemplo, a atribuição de cinto para evitar a queda de trabalhadores na realização de trabalhos em altura) pode gerar outros riscos não identificados à partida e que podem ser iguais ou superiores àquele que se pretende prevenir. 
46 A rejeição dos dispositivos de segurança, particularmente os equipamentos de protecção individual, pode ter origem em muitos outros aspectos, eventual-mente menos objectivos, tais como questões de identidade ou de controlo social ao nível laboral. Como afirma Dwyer: "De maneira diferente, a rejeição pode se dar porque os dispositivos e as regras de segurança são vistos como símbolos de dominação 'injusta' do empregador, ou porque são feios, atrapalham o desempenho, são mal planejados e, como tais, são percebidos como uma afronta à dignidade e ao conforto pessoais" (Dwyer, 2006: 183). No entanto, quando os trabalhadores utilizam este tipo de argumentação acabam por perder alguma legitimidade moral para reclamarem melhores condições de segurança nos seus locais de trabalho.

Face ao exposto anteriormente, depreende-se que a segurança é uma maté-ria complexa no mundo do trabalho. Neste âmbito podemos encontrar alguns paradoxos que não seriam previsíveis à partida. 0 primeiro deles pode ser observado quando se verifica que a redução de acidentes causada por um dos quatro níveis apresentados na Figura 1 pode dar origem ao aumento dos acidentes causados por qualquer outro dos três níveis restantes. Isto significa que nem sempre a redução de acidentes num nível dá origem a que os outros permaneçam com a mesma "capacidade" de influência sobre a totalidade dos acidentes (Dwyer, 2006: 214). É possível encontrar outro paradoxo quando observamos que, em certas situações, os locais de trabalho aparentemente mais perigosos apresentam índices inferiores de acidentes de trabalho, enquanto determinados locais de trabalho considerados seguros e cumpridores das regras e normas de segurança revelam elevadas taxas de sinistros laborais (Dwyer, 2006: 202). Esta situação pode estar relacionada com o tipo de percepções formuladas pelos trabalhadores, sabendo que os postos de trabalho mais seguros podem suscitar a diminuição da vigilância sobre os riscos ocupacionais, ou, inversamente, os postos de trabalhos menos seguros podem reforçar a sua vigilância.

\section{Novos caminhos de reflexão para a teoria social dos acidentes}

Alguns estudos mais recentes têm vindo a demonstrar que a génese dos acidentes está incorporada na própria história das organizações, nomeadamente em aspectos relacionados com as decisões estratégicas da gestão de topo (Sagan, 1993; Vaughan, 1996, 1999; Rasmussen, 1997; Reason, 1997), na escolha de determinadas técnicas e tecnologias (Perrow, 1999), no design dos postos e locais de trabalho, nas formas de organização e planeamento das tarefas, na especificidade dos riscos de cada organização (Areosa, 2009d), no tipo de gestão efectuada ao nível da manutenção (Reason e Hobbs, 2003), nas formas de compreender e "gerir" os incidentes, no tipo de resiliência da organização (Hale e Heijer, 2006), na insuficiência das regras, normas e procedimentos para a prevenção de acidentes (Areosa, 2010), para além de certas dimensões externas à própria organização, tais como, políticas governamentais, legislação (por inadequação ou ausência) ou problemas relacionados com fornecedores exter-nos. Todos estes contextos podem ir fragilizando o próprio sistema até estarem reunidas as condições necessárias para ocorrer o acidente (Turner, 1978). É por este motivo que corroboramos a opinião de diversos autores (Reason, 1990; D'Oliveira, 2006; Dekker, 2006) que defendem que atribuir a principal causa dos acidentes ao erro humano é uma visão muito limitada que serve como uma ideologia de poder, acabando por negar o papel das relações sociais na produ ção desses mesmos acidentes. 
49 Por outras palavras, tal como refere Llory (1999), continuar a atribuir a culpa dos acidentes aos trabalhadores hierarquicamente inferiores pode ser interpretado como uma "cegueira maciça”, à qual pode estar subjacente a ideia de poupar responsabilidades às hierarquias das organizações. Para além disso, Amalberti (1996) refere que muitos acidentes são evitados graças aos trabalhadores que actuam nas organizações (ideia compatível com as noções de auto-recompensa, auto-comando e auto-organização de Dwyer).

50 Julgamos que a sociologia, em articulação com outras disciplinas interessadas em aprofundar o debate sobre os acidentes, pode ajudar a desenvolver novas formas de compreensão sobre como ocorrem certos tipos de "erros" em meio laboral. É importante aprofundar o nosso conhecimento acerca das estratégias cognitivas dos trabalhadores durante o exercício da sua actividade profissional, assim como "dar voz" às suas subjectividades (mesmo que outros as possam interpretar como sendo aparentemente "irracionais"). Quando ocorrerem acidentes, mais importante do que tentar encontrar culpados ou partir imediatamente do pressuposto que foram cometidos determinados erros humanos, parece fazer mais sentido tentar entender quais as possíveis pressões a que os trabalhadores estavam sujeitos no momento do acidente (confl itos com colegas e hierarquias, incertezas e dilemas nos julgamentos, sobrecarga de trabalho, incapacidade para manter permanentemente níveis elevados de atenção, difi culdades para cumprir determinado tipo de normas, ou ainda outros aspectos individuais, tais como o medo de perder o emprego, o estado de saúde, a ansiedade e a frustração ou a revolta com certas injustiças sociolaborais). Para além disso, é também importante compreender que, por vezes, existem profundas descoincidências entre o trabalho prescrito pelo empregador e o trabalho real, ou seja, a forma como o trabalho é efectivamente realizado pelos trabalhadores (Silva, 2003). Isto pode enviesar toda a estratégia de prevenção da organização, dado o eventual desconhecimento sobre o funcionamento real do "chão-dafábrica". A nível organizacional, parece ainda possível à teoria sociológica observar a importância de factores como a resiliência ou as barreiras de segurança ${ }^{4}$, enquanto factores que podem influenciar o número de acidentes. É relevante podermos considerar como é que estes e outros factores podem infl uenciar a dinâmica do mundo do trabalho e, em certos casos, produzir acidentes.

51 Numa abordagem algo inovadora, mas não isenta de alguma controvérsia, Hollnagel (2004) preconiza que determinados acidentes podem ser vistos como uma infeliz agregação de factores e condições diversificadas, passíveis de produzir um evento não desejado. $O$ autor distingue entre explicações e causas para os acidentes, defendendo que, por vezes, pode ter maior utilidade procurar as explicações em vez das suas causas. As explicações para os acidentes partem do alinhamento ou articulação simultânea de vários factores ou condições que permitiram o culminar de um determinado evento (o acidente), embora seja possível que nenhum deles, isoladamente, tenha capacidade para originar este tipo de evento. Portanto, isso não nos permite afirmar que esse acidente tenha sido gerado por uma causa específica.

52 Existe um longo e antigo debate em torno da questão da atribuição de causas únicas ou múltiplas aos acidentes. A resposta depende, em parte, da posição do actor no sistema social. No caso dos juristas, interessados em apurar a responsabilidade civil e criminal, pode haver a tendência para procurar uma causa única. Contemplar a ideia de que as causas podem ser múltiplas é reconhecer a divisão de responsabilidades e a difícil determinação do peso de cada uma delas na produção do evento. Já para alguns teóricos 
das organizações, procurar as raízes das causas (associadas à multicausalidade) pode ser tão ou mais importante do que restringir a análise à designada causa imediata (regra geral a mais próxima ao momento do acidente), porque isto permite detectar as diversas condições e/ou erros que estiveram subjacentes ao evento. Raouf (1998), recorrendo à teoria dominó preconizada por Heinrich (1931), procura reconciliar estas duas posições distintas, mas este tema está longe de reunir consensos e de estar encerrado. Prova disto mesmo é o facto de nós (autores deste texto) divergirmos na forma como olhamos para esta questão. Contudo, uma das possíveis explicações para esta diferença pode estar naquilo a que cada autor procura responder com a sua análise; isto é, Dwyer (2006) tende a preocupar-se com o problema da responsabilização, enquanto Areosa (2010) centra a sua atenção nos diversos factores que podem ter conduzido ao acidente.

Já referimos que o alinhamento de factores ou condições constituem uma explicação para o acidente, visto que nos permite compreender como ele ocorreu, ainda que não seja a "causa" em si mesmo. A existir uma causa, será a extraordinária coincidência do alinhamento destes factores. De certo modo, a explicação para alguns acidentes não significa o mesmo que a sua causa. Tal como refere Hollnagel:

The difference between looking for explanations and for causes is therefore crucial. If accidents have causes, then it makes sense to try to find them and to do something about them once found. If accidents have explanations, then we should rather try to account for how the accident took place and for what the conditions or events were that led to it. The response should not be to seek out and destroy causes, but to identify the conditions that may lead to accidents and fi nd effective ways of controlling them. (Hollnagel, 2004: 29)

Conforme se pode verificar, existem novos aspectos que devem ser considerados e aprofundados para obter um melhor entendimento sobre os acidentes. Este campo de observação tem aumentado as suas dimensões de análise e isto pode permitir a ampliação do nosso conhecimento sobre este fenómeno social (o acidente), até recentemente visto como não social ou como não tendo nenhuma infl uência das relações sociais.

\section{BIBLIOGRAPHY}

AMALBERTINI, René (1996), La Conduite des systèmes à risques, Paris, Le Travail Humain / Presses Universitaires de France.

AREOSA, João (2003), "Riscos e acidentes de trabalho: inevitável fatalidade ou gestão negligente?", Sociedade e Trabalho, 19/20, 31-44.

AREOSA, João (2005), “A hegemonia contemporânea dos 'novos' riscos”, in Carlos Guedes Soares et al. (Orgs.), Análise e Gestão de Riscos, Segurança e Fiabilidade, Lisboa, Edições Salamandra, 203-218.

AREOSA, João (2007), “As percepções de riscos dos trabalhadores: conhecimento ou 'iliteracia'?”, in Colóquio Internacional de Segurança e Higiene Ocupacionais - SHO2007, Guimarães, 131-134.

AREOSA, João (2008), "Risco e análise de riscos: contributos para a sua conceptualização", in Colóquio Internacional de Segurança e Higiene Ocupacionais - SHO2008, Guimarães, 45-50. 
AREOSA, João (2009a), “Do risco ao acidente: que possibilidades para a prevenção?", Revista Angolana de Sociologia, 4, 39-65.

AREOSA, João (2009b), "O risco no âmbito da teoria social: quatro perspectivas em debate", Revista Brasileira de Informação Bibliográfica em Ciências Sociais (BIB), 68, 59-76.

AREOSA, João (2009c), "Riscos de uma actividade de risco: um estudo de caso em contexto hos pitalar", Configurações, 5/6, 225-239.

AREOSA, João (2009d), “Organizações de alta fiabilidade: que limites para a segurança?", in Carlos Guedes Soares et al. (Orgs.), Riscos Industriais e Emergentes, Lisboa, Edições Salamandra, 1077-1093.

AREOSA, João (2010), Riscos e Sinistralidade Laboral: Um estudo de caso em contexto organizacional, Tese de Doutoramento, Instituto Universitário de Lisboa (ISCTE-IUL), Lisboa, Portugal.

AREZES, Pedro (2002), Percepção do Risco de Exposição Ocupacional ao Ruído, Tese de Doutoramento, Universidade do Minho, Guimarães, Portugal.

BECK, Ulrich (1992), Risk Society. Towards a New Modernity, Londres, Sage.

BURNS, Tom e MACHADO, Nora (2009), "Technology, complexity and risk: Social systems analysis of risky socio-technical systems and the likelihood of accidents", Sociologia, Problemas e Práticas, 61, 11-40.

DEJOURS, Christophe (1991), A Loucura do Trabalho, São Paulo, Cortez Editora.

DEKKER, Sidney (2006), The Field Guide to Understanding Human Error, Hampshire: Ashgate.

D'OLIVEIRA, Teresa (2006), “Acidentes organizacionais e factores humanos”, in Jorge Gomes; Miguel Cunha e Arménio Rego (Orgs.), Comportamento Organizacional e Gestão. Lisboa, Editora RH.

DWYER, Tom (1989), “Acidentes do trabalho: Em busca de uma nova abordagem”, Revista de Administração de Empresas, 29, 19-32.

DWYER, Tom (1991), Life and Death at Work: Industrial accidents as a case of socially produced error, Nova Iorque, Plenum.

DWYER, Tom (2000a), "Novas fronteiras nos estudos do trabalho", in Encontro anual da ANPOCS, Petropólis, 1-24.

DWYER, Tom (2000b), “A produção social do erro - O caso dos acidentes ampliados”, in Carlos Freitas, Marcelo Porto e Jorge Machado (Orgs.), Acidentes Industriais Ampliados: Desafi os e perspectivas para o controle e a prevenção, Rio de Janeiro, Editora Fiocruz, 107-126.

DWYER, Tom (2006), Vida e Morte no Trabalho: Acidentes do trabalho e a produção social do erro, Rio de Janeiro e Campinas, Multiação Editorial e Editora da UNICAMP.

DWYER, Tom \& ELGSTRAND, Kaj (2009), “A new OSH paradigm is needed”, in Kaj Elgstrand e Nils Petersson (Eds.), OSH for Development, Estocolmo, Royal Institute of Technology, 46-61.

ESPAÑOL, Esther (2001), “La conducta humana frente a los riesgos laborales. Determinantes indi viduales y grupales", Acciones e Investigaciones Sociales, 12, 157-184.

FREIRE, João (1991), "Imigrantes, capatazes e segurança no trabalho da construção civil”, Organizações e Trabalho, 5/6, 147-153.

FURNHAM, Adrian (1992), Personality at work: The role of individual differences in the workplace, Londres, Routledge. 
GIBSON, J. (1961), “The contribution of experimental psychology to the formulation of the prob lem of safety - a brief for basic research", Behavioral Approaches to Accident Research, Nova Iorque, Association for the Aid of Crippled Children, 77-89.

GORDON, John (1949), “The epidemiology of accidents”, in American Journal Public Health, 39, 504-515.

GRANJO, Paulo (2004), Trabalhamos sobre um Barril de Pólvora: Homens e perigo na refi naria de Sines, Lisboa, Imprensa de Ciências Sociais.

GREENWOOD, M. \& WOODS, H. M. (1919), "The incidence of industrial accidents upon individuals with special reference to multiple accidents", Industrial Fatigue Research Board, Medical Research Committee, Report No. 4, Her Majesty's Stationery Offi ce, Londres.

HALE, Andrew \& HALE, M. (1972), A Review of the Industrial Accident Research Literature, Londres, HMSO.

HALE, Andrew \& HEIJER, Tom (2006), “Defining Resilience”, in Erik Hollnagel; David Woods e Nancy Leveson (Eds.), Resilience Engineering: Concepts and Precepts, Aldershot, Ashgate Publishing. HEINRICH, Herbert (1931), Industrial Accident Prevention, Nova Iorque, McGraw-Hill.

HOLLNAGEL, Erik (2004), Barriers and Accident Prevention, Hampshire, Ashgate.

HOVDEN, Jan, ALBRECHTSEN, Eirik \& HERRERA, Ivonne (2010), "Is there a need for new theories, models and approaches to occupational accidents prevention?", Safety Science, 48, 950-965.

HUNTER, David (2002), Risk Perception and Risk Tolerance in Aircraft Pilots, Washington, Federal Aviation Administration.

LAPORTE, Todd \& CONSOLINI, Paula (1991), “Working in practice but not in theory: Theoretical challenges of 'High-Reliability Organizations"', Journal of Public Administration Research and Theory, $1,19-48$.

LEGER, P. (1986), "Safety and organization of work in South African gold mines: A crisis of con trol”, International Labour Review, 125, 591-603.

LLORY, Michel (1999), Acidentes Industriais: $O$ custo do silêncio, Rio de Janeiro, Multimais.

Marx, Karl (1966 [1867]), O Capital, São Paulo, Editora Nova Cultural Ltda.

PERROW, Charles (1999), Normal Accidents: Living with high-risk technologies, New Jersey, Princeton University Press.

PINTO, José Madureira (1996), "Contributos para uma análise dos acidentes de trabalho na cons trução civil”, Cadernos de Ciências Sociais, 15/16, 87-119.

RAOUF, Abdul (1998), Theory of Accident Causes. International Labour Organization's Encyclopedia of Occupational Health and Safety, Geneva, ILO (4' edição).

RASMUSSEN, Jens (1997), "Risk management in a dynamic society: A modeling Problem", Safety Science, 27, 183-213.

REASON, James (1990), Human Error, Cambridge, Cambridge University Press.

REASON, James (1997), Managing the Risks of Organizational Accidents, Aldershot, Ashgate.

REASON, James (2008), The Human Contribution: Unsafe acts, accidents and heroic recoveries, Farnham, Ashgate.

REASON, James \& HOBBS, Alan (2003), Managing Maintenance error: a practical guide, Hampshire, Ashgate. 
ROBERTS, Karlene (1990), "Some characteristics of one type of High Reliability Organization”, Organization Science, 1, 160-176.

SAGAN, Scott (1993), The Limits of Safety: Organizations, accidents and nuclear weapons, Princeton, NJ, Princeton University Press.

SILVA, Sílvia (2003), Culturas de Segurança e Prevenção de Acidentes de Trabalho numa Abordagem Psicossocial: Valores organizacionais declarados e em uso, Tese de Doutoramento, Lisboa, ISCTE.

SJOBERG, Lennart (1999), "Risk perception by the public and by experts: A dilemma in risk mana gement”, Research in Human Ecology, 6, 1-9.

THEYS, Jacques (1987), “La société vulnérable”, in Vidal Cohen et al., La Société vulnérable, Paris, Presses de L'École Normale Supérieure.

TURNER, Barry (1978), Man Made Disasters, Londres, Wykeham Press.

VAUGHAN, Diane (1996), The Challenger Launch Decision: Risky technology, culture and deviance at NASA, Chicago, University of Chicago Press.

VAUGHAN, Diane (1999), "The dark side of organizations: Mistake, misconduct, and disaster", Annual Review of Sociology, 25, 271-305.

WEICK, Karl (1987), “Organizational culture as a source of high reliability”, California Management Review, 29, 112-127.

WEICK, Karl \& STUCLIFFE, Kathleen (2007), Managing the Unexpected: Resilient performance in an age of complexity, San Francisco, John Wiley \& Sons.

\section{NOTES}

1. Um dos objectivos deste texto é divulgar a teoria dos acidentes de Dwyer, pois esta abordagem (ainda pouco conhecida em Portugal) pode ajudar a compreender este fenómeno. Contudo, além das perspectivas acima referidas, ainda podemos referir outras abordagens importantes dentro deste domínio, nomeadamente, a teoria da propensão individual para os acidentes (Greenwood e Woods, 1919), a teoria dominó preconizada por Heinrich (1931), o modelo epidemiológico dos acidentes (Gordon, 1949), a perspectiva da transferência de energia e das barreiras protectoras (Gibson, 1961) ou o modelo da migração sistémica para o acidente (Rasmussen, 1997).

2. As referidas hipóteses de análise são as seguintes: "1. As relações sociais de trabalho produzem acidentes; 2. Quanto maior o peso de um nível de relações sociais na gestão das relações dos trabalhadores com os perigos de suas tarefas, maior a proporção de acidentes produzidos nesse nível; 3. Quanto maior o grau de gestão da segurança pela administração em um nível, menor a proporção de acidentes produzidos no nível que essa ação procura controlar; 4. Quanto maior o grau de autocontrole pelos trabalhadores em um nível, menor a proporção de acidentes produzidos no nível que a ação do trabalhador procura controlar" (Dwyer, 2006: 260).

3. Nos antípodas desta teoria surgem outras teorias que defendem que a ultrafamiliaridade com algumas situações de risco (trabalhos de rotina) pode originar desatenções e, por consequência, aumentar o número de acidentes.

4. Na perspectiva de Hollnagel (2004), as barreiras são normalmente entendidas como um obstáculo, uma obstrução ou um entrave à ocorrência de um determinado evento ou, caso não o consigam "travar", pelo menos tendem a diminuir o impacto das suas consequências. Assim, as barreiras podem ter funções distintas; por um lado, podem tentar evitar ou "impossibilitar" um evento (barreiras preventivas), por outro lado, podem tentar suavizar, enfraquecer ou atenuar os efeitos de um determinado evento (barreiras protectoras). 


\section{ABSTRACTS}

A sociologia nacional parece ainda não ter dado a merecida importância à temática dos acidentes de trabalho, considerando que são relativamente escassas as suas publicações sobre este assunto. Um dos principais contributos da sociologia para a compreensão e interpretação dos acidentes de trabalho é a ampliação das possíveis explicações destes eventos, bem como a identifi cação de novos factores que possam contribuir para a sua prevenção. Para esta disciplina os acidentes não derivam apenas de causas individuais ou de condições materiais perigosas, derivam, sobretudo, de causas sociais. São estas causas que pretendemos discutir. Na parte final deste artigo iremos tentar traçar novos caminhos para a análise sociológica dos acidentes de trabalho, em articulação com outras disciplinas científicas, tentando colmatar alguns limites da teoria sociológica.

Il paraît que la sociologie portugaise n'a pas donné assez d'importance au thème des accidents du travail, si l'on pense au petit nombre de publications sur le thème. Une des principaux apports de la sociologie pour la compréhension et interprétation des accidents du travail est de permettre à augmenter le nombre d'explications possibles de ces événements, ainsi que l'identification des nouveaux facteurs qui peuvent faire une contribution à leur prévention. Pour la sociologie les accidents ne doivent pas être vus ni comme résultat de l'opération des facteurs individuels, ni comme conséquence des conditions dangereuses, mais surtout des causes sociaux. Ce sont ces causes que nous voulons discuter ici. À la fi $\mathrm{n}$ de l'article nous allons indiquer des nouveaux chemins pour des analyses des sociologique des accidents du travail en dialogue avec autres disciplines scientifiques, aussi nous montrerons quelques limitations de la théorie sociologique.

Portuguese sociology seems to have not given the deserved importance to the workplace accident issue, as the publications on this subject are scarce. One of the major sociology contributions to understand and interpret occupational accidents is on the introduction of new possible explanations for these events, as well as the identification of factors that have not yet been contemplated and which may contribute to their prevention. For this discipline accidents are not simply caused by individual factors nor by hazardous materials conditions as their causes are mainly social. These are the causes that we intend to discuss. At the end of this paper we will try to trace new directions for the sociological analysis of occupational accidents in articulation with other scientific disciplines, trying to overcome some limits of the sociological theory.

\section{INDEX}

Mots-clés: risques professionnels, accidents du travail, théorie sociale, sociologie du travail Keywords: occupational risk, occupational accidents, social theory, sociology of work Palavras-chave: riscos ocupacionais acidentes de trabalho, teoria social, sociologia do trabalho 


\section{AUTHORS}

\section{JOÃO AREOSA}

Centro de Investigação em Ciências Sociais joao.s.areosa@gmail.com

\section{TOM DWYER}

Universidade Estadual de Campinas tom@unicamp.br 